\title{
Resistencia Legítima frente al conflicto colombiano. Una reflexión teórica a partir de una Comunidad de Paz ${ }^{1}$
}

\author{
Philipp Naucke²; Ernst Halbmayer ${ }^{3,4}$
}

Recibido: 22 de abril 2015 / Aceptado: 1 de diciembre de 2015

Resumen. Este artículo reflexiona sobre las opciones por parte de civiles de resistir pacíficamente en conflictos armados. Los argumentos desarrollados aquí se basan en una investigación de campo en la Comunidad de Paz de San José de Apartadó, Colombia. El marco analítico y teórico por medio del cual se delimita en este artículo la aplicación del término 'resistencia', se basa en las consideraciones conceptuales de Hollander y Einwohner (2004) y en el concepto teórico de 'resistencia legítima' de O’Brien (1996). Después de un breve análisis del conflicto, describiremos los procesos socio-históricos de la zona de Apartadó, y las experiencias auto-organizativas de sus habitantes, las cuales favorecieron la conformación de esta iniciativa de paz. El análisis de las dimensiones y de los objetivos de la resistencia de la Comunidad de Paz permite reconceptualizar la idea de 'resistencia legítima' de O'Brien.

Palabras clave: Resistencia; Población Civil; Conflicto Armado; Comunidad de Paz.

\section{[en] Rightful Resistance in the Colombian conflict. A theoretical reflection based on a Peace Community}

\begin{abstract}
This article considers the opportunities of civilians to peacefully resist violent conflicts or civil wars. The argument developed here is based on a field-based research on the peace community San José de Apartadó in Colombia. The analytical and theoretical framework, which delimits the use of the term 'resistance' in this article, builds on the conceptual considerations of Hollander and Einwohner (2004) and on the theoretical concept of 'rightful resistance' developed by O'Brien (1996). Beginning with a conflict-analytical classification of the case study, we will describe the long-term socio-historical processes and the organizational experiences of the civilian population, which favoured the emergence of this resistance initiative. The analytical approach to the dimensions and aims of the resistance of this peace community leads to the differentiation of O'Brian's concept of 'rightful resistance'.
\end{abstract}

Keywords: Resistance; Civilian Population; Armed Conflict; Peace Community.

1 Fuente de financiación: Deutsche Forschungsgemeinschaft (DFG) - GZ: HA 5957/7-1

2 Philipps-Universität Marburg (Alemania)

philipp.naucke@uni-marburg.de

3 Philipps-Universität Marburg (Alemania)

ernst.halbmayer@uni-marburg.de

4 Los autores trabajan actualmente en un proyecto de investigación titulado "Resistencia civil, entre la autoprotección colectiva y la pacificación local - Comunidades de Paz en los conflictos armados de Colombia y Guatemala" financiado por la Deutsche Forschungsgemeinschaft- DFG (GZ: HA 5957/7-1). Agradecemos a los dos revisores anónimos por sus comentarios valiosos y a Camilo Alberto Robayo Romero y a Johanna Fernández por su ayuda en la traducción del texto. 
Cómo citar: Naucke, P., Halbmayer, E. (2016). Resistencia Legítima frente al conflicto colombiano. Una reflexión teórica a partir de una Comunidad de Paz, en Revista de Antropología Social 25(1), 9-33.

Sumario. 1. Introducción. 2. El conflicto colombiano. 3. La conformación de Comunidades de Paz. 3.1. 'La violencia' y sus consecuencias. 3.2. Auto-organización del poblado. 3.3. La ausencia estatal. 3.4. El desarrollo autónomo. 3.5. La persecución militar. 3.6. Alejamiento y oposición. 4. El uso analítico del concepto 'resistencia'. 5. La resistencia de la Comunidad de Paz. 6. Una reflexión del concepto 'resistencia legítima'. 7. Conclusiones. 8. Referencias bibliográficas.

\section{Introducción}

Comunidad de Paz San José de Apartadó, 27de marzo del 2008: estaba sentado en la mesa con E. en una casita en 'San Josecito', tomando algunas notas. Estábamos conversando cuando cerca de las 9:30 pm nos buscó Don P. aparentemente preocupado. En el camino que conecta la capital municipal Apartadó con el corregimiento San José de Apartadó, justo en frente de la bodega de la Comunidad de Paz acababan de llegar dos camionetas con soldados. Agarramos nuestras linternas y comenzamos a caminar. Durante los dos minutos de trayecto hacia la bodega E. le dio instrucciones a personas que no pude reconocer en la oscuridad. Había que llamar a las Brigadas de Paz para informarles sobre la presencia del ejército. E. expresó el temor de que podría ser un allanamiento de la Comunidad de Paz. Desde días se escuchaban rumores según los cuales el ejército lo habría planeado. Cuando llegamos a la pequeña plaza destinada a la carga y descarga de la bodega, que a esta hora estaba iluminada con una bombilla de escasa luz, encontramos dos camiones y unos 30 soldados. La plaza en sí pertenece a la vía pública. Tanto la casa de la bodega, así como el predio al lado de la vía pertenece a la Comunidad de Paz. Su territorio está marcado con cercas y señales, en las cuales están escritas las reglas de la Comunidad; entre otras no se les permite a los grupos armados el acceso a su territorio. Detrás de la cerca ya se encontraba un pequeño grupo de residentes observando con mirada escéptica lo que estaba sucediendo en la plaza de la bodega. Los soldados habían apoyado sus fusiles contra la pared de madera de la bodega, mientras se ocupaban de descargar los camiones. Antes de entrar a la plaza E. me susurró que no me alejara de su lado. Luego empezó a preguntar a los soldados por el comandante quien se dio a conocer de forma vacilante y reticente. E. le preguntó qué estaban haciendo los soldados allí. El comandante respondió con una pregunta retórica, si E. vive desde hace tiempo aquí debería saber lo que estaba pasando. Con los camiones no habían podido subir más por el camino, por eso decidieron descargar sus cosas aquí. E., quien vino a la región con su padre cuando tenía ocho años a finales de los 60 , respondió muy formalmente que cada día varios camiones subían este camino sin ningún problema. Añadió que la presencia de la unidad militar ponía en riesgo a la población civil y que además ignoraba la sentencia de la Corte Interamericana de Derechos Humanos, que otorgó una protección especial a la Comunidad de Paz. El comandante contestó que los soldados están aquí para defender la ley y que se iban a ir en unos 10 minutos. Regresamos por un momento detrás de la cerca. Don P. preguntó si debería movilizar a los miembros de la Comunidad. E. lo negó con la mano; se debería informar de nuevo a las Brigadas de Paz y esperar con un pequeño grupo de miembros la retirada de los 
soldados. E. se acercó de nuevo al comandante para asegurarse de que sus soldados no olvidarán nada, ni siguiera su basura. Después nos sentamos, ocho miembros de la comunidad y yo, a un lado de la plaza a observar la situación, un escenario de guerra como de película. Entre tanto, el suelo de la plaza se había llenado de más armas de diferentes tamaños y tipos; de alimentos como arroz, frijoles y aceite, así como de productos de uso básico como ollas, baldes y tazones. Estos fueron distribuidos a los soldados. Algunos de ellos eran jóvenes, tenían puesto su uniforme de combate que consistía en botas de caucho, cintas de munición y gafas militares, y que con gesto preocupado empacaron las cosas en sus mochilas. Nosotros apenas si hablábamos, todos miraban serio o jugaban nerviosamente con sus manos. Sólo J., con quien compartía unos días la casa, susurró una broma sobre allanamientos - nadie se rió. Cuando después de hora y media los soldados finalmente se retiraron, todos los residentes presentes revisaron la plaza de la bodega y el edificio adyacente. E. estalló de rabia vociferando en contra de la arrogancia del ejército. Nadie encontró algo sospechoso. Se esperaba que hubiese un allanamiento al día siguiente, pero no fue así (Naucke, diario de campo, 2008).

Las regiones en conflicto de Colombia se pueden reconocer por la presencia limitada del Estado y por la de diferentes actores armados legales e ilegales, quienes luchan por controlar el territorio con un alto grado de violencia. Por lo general, se le adscribe a la población civil solo el papel de víctima inocente, que ante la confrontación armada no tiene otra opción que colaborar con uno de los actores armados o abandonar la región ${ }^{5}$. Las Comunidades de Paz se escapan de esta imagen de víctima, ya que asumen el derecho de tomar una posición neutral frente a las partes en conflicto, constituyendo así una forma de resistencia pacífica comunitaria (Valenzuela, 2010). A pesar de que a finales de los años 90 varios pueblos se declararon Comunidades de Paz, no existe un concepto homogéneo de las mismas. Las características concretas de cada Comunidad de Paz dependen de las particularidades regionales y locales del conflicto. Lo que todas tienen en común, sin embargo, es que sus habitantes se definen como parte de la población civil no combatiente, que no quiere ser involucrada en las confrontaciones armadas ni colaborar con los actores bélicos. En este artículo se examinará a modo de ejemplo el caso de San José de Apartadó, que fue uno de los primeros pueblos en Colombia que en 1997 se declaró Comunidad de Paz. Los habitantes de San José de Apartadó desarrollaron una estructura organizativa interna y una serie de estrategias - tanto cotidianas y a medio plazo- que les han permitido existir en la región de Urabá, uno de los territorios más violentos del conflicto armado.

En este artículo nos proponemos, en primer lugar, reflexionar acerca de la opción por parte de civiles de actuar pacíficamente en conflictos armados. En segundo lugar, planteamos desarrollar el concepto teórico de la 'resistencia legítima' de O'Brien (1996). Iniciaremos describiendo el contexto social y analizando brevemente el conflicto colombiano. Seguidamente presentaremos el caso de la Comunidad de San José de Apartadó, describiendo las causas y el proceso de su formación. A continuación, introduciremos la resistencia como concepto analítico para aplicarlo al caso de la Comunidad de Paz. Este análisis nos llevará a la reflexión y diferenciación del concepto teórico de 'resistencia legítima', con el cual finalizaremos este artículo.

Ver por ejemplo el análisis de la mayoría de los reportes en los medios de comunicación o de organizaciones de derechos humanos (p.ej. Amnistía Internacional, 2008) sobre conflictos actuales (también Bonacker, 2013). 
Los apartados que contienen descripciones de la Comunidad de Paz (sobre todo los apartados 3 y 5) se basan en un trabajo de campo de tipo multi-temporal (Bräuchler, 2015) llevado a cabo por Philipp Naucke en los años 2008, 2013 y 2015. En las diferentes estancias, cada una de tres meses, Naucke tuvo la oportunidad de visitar diferentes veredas de la comunidad y hablar tanto con sus habitantes como con personas que han acompañado el proceso ${ }^{6}$.

\section{El conflicto colombiano}

Comunidad de Paz San José de Apartadó, 29 de marzo del 2008: antes de que el ataúd desapareciera en el suelo rojizo que contrastaba con el verde oscuro de la pradera y del bosque subyacente, se abrió de nuevo. Al cadáver, el de un chico de 16 años, casi un niño, los familiares y amigos le añadieron artículos personales tales como zapatos de fútbol y ropa. Al mirar en el ataúd me sorprendió que la cabeza y la cara del joven parecieran ilesas, - me había imaginado de otra manera a alguien asesinado por disparos en la cabeza. El funeral del muchacho era el último capítulo de una muerte anunciada, que a pesar de ello no sería aclarada, una de las muchas muertes anunciadas e inexplicables en la historia del conflicto colombiano. El 25 de marzo del 2008, cuatro días antes del funeral del muchacho, la emisora de radio del ejército en Apartadó informó que se habían presentado combates entre la guerrilla y el ejército en la zona alrededor de San José de Apartadó, donde murió un guerrillero. La noticia fue recibida por los campesinos locales con escepticismo, pues en los días anteriores se habían visto muchos soldados en la zona; pero ningún campesino sabía de nuevos enfrentamientos. Rápidamente expresaron el temor de que el guerrillero muerto podría ser un campesino. Dos días después, una familia de la zona, que no era parte de la Comunidad de Paz, se acercó al Consejo Interno de la Comunidad pidiendo ayuda. De los aproximadamente 3.000 campesinos que viven en el corregimiento de San José de Apartadó, sólo un tercio son miembros de la Comunidad de Paz; aunque cabe señalar que la relación entre los miembros y no miembros de la Comunidad es amable y solidaria. La familia pidió al Consejo Interno de la Comunidad ayuda para organizar los trámites necesarios para reclamar el cuerpo de su hijo en Medicina Legal de Apartadó y transportarlo a San José de Apartadó. Su hijo fue asesinado a tiros en el municipio vecino de Carepa dos días antes por militares. El 28 de marzo nos fuimos - E., G., un familiar del muchacho y yo- a Apartadó. Con el apoyo del Comité Internacional de la Cruz Roja lograron que el cuerpo del muchacho fuera entregado por Medicina Legal a una funeraria, que organizó el traslado a San José de Apartadó, donde lo enterraron al día siguiente. Ni Medicina Legal ni el ejército dieron información sobre las circunstancias de su muerte y mantuvieron la versión de que el joven habría muerto en combate con la guerrilla en la zona de San José de Apartadó. Ya el mismo día de su funeral circulaba una serie de rumores acerca de su suerte. Algunos afirmaban que el joven de verdad hacía parte de la guerrilla, y que viajaba a Carepa para cobrar una 'vacuna' - un dinero producto de extorsiones - donde fue sorprendido y asesinado por los militares. Otros contaban que él había estado con la guerrilla, pero como quería escapar, fue ejecutado por la

6 Debido a la brevedad del artículo y en aras de la coherencia, sólo se utilizarán datos etnográficos de la investigación del año 2008. 
misma. La mayoría de los campesinos de la zona no creían que el joven fuera capaz de hacer parte de la guerrilla y veían en él a uno de los muchos jóvenes inocentes asesinados por el ejército, hoy en día conocidos como 'falsos positivos'. Solo existía consenso acerca de que la versión oficial, según la cual el muchacho habría caído en un combate con la guerrilla en la zona alrededor de San José de Apartadó, era falsa y de que le habían disparado en la cabeza desde una distancia corta (Naucke, diario de campo).

Desde hace más de 50 años Colombia es escenario de un conflicto armado entre distintos movimientos guerrilleros, grupos paramilitares y la fuerza pública. El narcotráfico ha jugado en este un papel significativo, por un lado por ser una fuente de financiación para los grupos armados (Mertins, 2001: 50), y por otro, por constituir un actor armado autónomo en cuanto a criminalidad organizada. El Estado colombiano no ha mantenido el monopolio de la violencia dentro de todo el territorio colombiano en ningún momento desde su existencia, y tampoco ha ejercido un control territorial de forma efectiva (ver p. ej. Sánchez y Chacón, 2006). En esa situación se fueron mezclando estrechamente distintas formas de violencia. En Colombia se fueron desarrollando diversos tipos de actores armados y los límites de sus campos de acción se han ido desdibujando: delincuencia común, delincuencia organizada, violencia política, acciones terroristas y violaciones de los Derechos Humanos tanto como del Derecho Internacional Humanitario ${ }^{7}$. Los límites de estas acciones han sido además definidos y reinterpretados por los diferentes actores según sus intereses particulares y según la coyuntura política del momento ${ }^{8}$.

La construcción y consolidación del Estado colombiano se caracterizan por ser parte de un prolongado proceso, lo que se nota no solo por la falta de control territorial, o sea en su dimensión estructural clásicamente definida por la unidad de pueblo, poder y territorio de un Estado (Jellinek, 1959), sino también por su dimensión funcional. Con esto se hace referencia según Schneckener (2006) al poder de gobernar del Estado (gobernanza), o sea, ofrecer a toda la población la garantía de vivir en seguridad, bienestar y bajo la autoridad de la ley. Basta con mencionar algunos datos actuales sobre el bienestar: en Colombia el 32,7\% de la población vive en condiciones de pobreza (PNUD, 2014: 210), solo el 23\% de la población mayor de 65 años recibe una pensión (PNUD, 2014: 231), y hasta el 70\% de los empleados trabaja en el sector informal (OECD, 2015: 30). Hasta hace algunos años esta situación era aún más grave, hasta el punto de que se ha visto al Estado colombiano al borde de la "desintegración funcional" (Heinz, 1997: 138).

Un factor importante dentro de las causas del conflicto colombiano es la distribución desigual de la prosperidad en la sociedad. Esta desigualdad social se refleja en un coeficiente de Gini de 55,9, donde al 10\% de la población pobre le pertenece solo el $0,8 \%$ del ingreso nacional y al $10 \%$ de la población rica pertenece el $45,9 \%$

\footnotetext{
La guerrilla, por ejemplo, se entiende como actor político, obtiene su financiación en parte del narcotráfico y comete tanto crímenes que vulneran los Derechos Humanos como acciones terroristas. Los paramilitares han tenido vínculos estrechos con políticos y miembros de instituciones estatales, han estado fuertemente involucrados en el narcotráfico y han cometido incluso crímenes de lesa humanidad. El ejército no solo toleraba muchas veces los operativos paramilitares, sino cometió también crímenes contra los Derechos Humanos y del Derecho Internacional Humanitario como los falsos positivos.

8 Parece que la importancia de los crímenes cometidos por actores armados ilegales cambia según las convicciones políticas del observador: por ejemplo, al ex-presidente Álvaro Uribe parece que no le han importado los crímenes cometidos por paramilitares tanto como le importan los crímenes cometidos por la guerrilla.
} 
del ingreso nacional (PNUD, 2014: 199). La pobreza, especialmente en las regiones rurales alcanza un nivel preocupantemente alto, donde un $75 \%$ de la población rural vive por debajo de la línea de pobreza (PNUD, 2011: 32) mientras 1,15\% de la población nacional posee el 52,2\% de la tierra (PNUD, 2011: 50).

Con el fin de entender el desarrollo del Estado colombiano consideramos a la violencia política como un elemento generador de orden y estructura. El sistema político tradicional con los partidos conservador y liberal ha sido históricamente muy limitado en cuanto a la participación de la población civil en la construcción de procesos políticos (Guillén Martínez, 2004). Sin embargo, a partir del siglo XIX se dieron numerosos conflictos violentos entre los dos partidos, en los que la población civil, a pesar de sus restringidas posibilidades de participación política, fue involucrada exitosamente, como se puede ver por ejemplo durante la época de la 'Violencia' (1948-53). Imponer intereses políticos por medio de la violencia y obligar a los civiles a tomar partido en esas luchas se convirtió en una estrategia general reconocida, que se aplicó en el siglo XX y se aplica en el siglo XXI (Waldmann, 1997). Así, Raul Zelik en su investigación sobre el desarrollo del paramilitarismo en Colombia, describe el uso del terror por parte del Estado como parte del manejo del gobierno colombiano (Zelik, 2009).

Según Kurtenbach (2004) las causas estructurales del conflicto armado en Colombia son las siguientes: 1) la no culminada consolidación del Estado, 2) la desigualdad social, 3) el sistema político tradicional, y 4) la independencia relativa de la violencia política. En este contexto, a partir de los años 60 se formaron movimientos guerrilleros y desde los años 80 grupos paramilitares y el narcotráfico. Después de 50 años de luchas violentas, que perduraron incluso a pesar de cambios políticos mundiales como el fin de la guerra fría, ya no es fácil distinguir con claridad las motivaciones y objetivos de cada actor. A través del tiempo el conflicto ha aumentado en complejidad.

Desde el 2012 el gobierno colombiano está negociando un acuerdo de paz con las FARC $^{9}$ (uno de los dos grupos guerrilleros restantes) en La Habana, Cuba ${ }^{10}$. Tras la desmovilización de grupos guerrilleros más pequeños en los años 90 (como p. ej. el Movimiento-19), las negociaciones en curso son el intento más serio de poner fin al conflicto armado. Después de tres años se han alcanzado acuerdos preliminares en cuatro de cinco puntos de la agenda y las dos partes han anunciado que terminarían las negociaciones para abril de 2016. Sin embargo, el progreso de las negociaciones no debe ocultar el hecho de que con un acuerdo de paz, Colombia se encontraría justo al comienzo de un proceso difícil y de larga duración. En éste se deben abordar las causas estructurales del conflicto y mejorar las condiciones de vida de la población pobre y de las víctimas del conflicto, si se espera que la paz sea sostenible (Naucke y Maihold, 2015). De las desmovilizaciones anteriores - incluyendo la reciente de los paramilitares (2002-2006) - es bien sabido que un acuerdo unilateral, con solo un grupo armado no cesa automáticamente los enfrentamientos bélicos en las regiones en conflicto de Colombia. Hasta el momento, ninguna negociación o desmovilización ha llevado a Colombia a alcanzar una paz duradera o ha significado el final de la violencia política.

\footnotetext{
La sigla FARC representa el nombre 'Fuerzas Armadas Revolucionarias de Colombia.'

10 El grupo guerrillero más pequeño, el ELN (Ejército de Liberación Nacional), todavía no hace parte de las negociaciones.
} 


\section{La conformación de Comunidades de Paz}

Comunidad de Paz San José de Apartadó, 23 de marzo del 2008: el día comienza a las 5:30 a.m. con música a todo volumen. El himno de la Comunidad de Paz suena por los altavoces. Las mujeres, equipadas con escobas y baldes, ya están en camino para limpiar la cocina común y el lugar techado con hojas de palma, donde la comunidad hace sus reuniones. Los hombres están limpiando con machetes las zonas verdes alrededor. Algunos niños tienen puestos sus mejores vestidos. Es el cumpleaños de la Comunidad. Hoy hace 11 años, durante un acto público celebrado el 23 de marzo de 1997 más de 500 personas firmaron la declaración de la Comunidad de Paz. Doña M. me cuenta, que contrariamente al año pasado en el que se ha celebrado este día en grande con delegaciones internacionales y discursos, este año no se ha planeado mucho. Habrá un almuerzo comunitario para el cual se ha matado una vaca. Además, se ha convocado una Asamblea General para el día de hoy, en la que hay que elegir un nuevo Consejo Interno. A la Asamblea llegan representantes de varias veredas del corregimiento de San José de Apartadó que pertenecen a la Comunidad de Paz. Como murieron dos viejos en la última semana también se ha cancelado el baile previsto para la noche por razones religiosas. Desde los altavoces ya se escucha el pequeño discurso de E. sobre la historia de la comunidad y la importancia de este día. Al terminar el discurso $\mathrm{E}$. les recuerda a todos que deben pagar sus facturas de electricidad pendientes. El $11^{\circ}$ aniversario de la Comunidad de Paz se celebraba en un día tranquilo en el que se recordaban especialmente a las personas de la región que en los últimos años fueron víctimas de la violencia por parte de todos los grupos armados (Naucke, diario de campo). Desde su fundación, la Comunidad que hoy tiene alrededor de 1000 personas afiliadas, registra más de 200 asesinatos, 11 masacres, así como más de 700 violaciones de derechos humanos y del derecho internacional humanitario (CdP San José de Apartadó, 2009).

La región del Urabá, situada en el noroeste de Colombia, estuvo dominada hasta los años 90 por los grupos guerrilleros FARC y EPL ${ }^{11}$. A mediados de esta década grupos paramilitares se propusieron tomar el control territorial de la región, lo que derivó en una escalada de violencia dirigida especialmente contra la población civil. Cabe señalar que con las FARC, el EPL y los Paramilitares solo se menciona a tres de un total de doce grupos armados que operaban a lo largo de los años 90 en la región (para un panorama completo de los actores armados en el Urabá, ver CINEP, 1995). En ese contexto de aumento de violencia y de amenazas de desplazamiento, el pueblo de San José de Apartadó se declaró en 1997 Comunidad de Paz. En la declaración sus pobladores se definieron como una parte de la población civil no combatiente y se comprometieron a no apoyar directa ni indirectamente a ningún actor armado (CdP San José de Apartadó, 1997a). A través de un proceso comunitario, los habitantes de San José de Apartadó desarrollaron una estructura organizativa que impulsaba la participación política de los pobladores y aseguraba la subsistencia y la independencia económica. De ahí en adelante se establecieron estrategias de autoprotección que han permitido la existencia de la Comunidad hasta la actualidad, a pesar de la represión masiva por parte de los actores armados (Hernández Delgado, 2004: 371).

11 La sigla EPL representa el nombre ‘Ejército Popular de Liberación'. 
Al revisar las cifras del desplazamiento forzado de la población rural en Colombia $^{12}$, parece más bien excepcional el hecho de que los habitantes de una región en conflicto decidan permanecer en su territorio sin colaborar con ninguno de los actores armados. Esto, teniendo en cuenta los enfrentamientos armados entre distintos actores legales e ilegales donde los civiles son objeto de agresiones sin poder confiar en el Estado para su protección. Bajo semejantes circunstancias por lo general se observa que la población es 'forzada' a abandonar la región, o a colaborar con alguno de los actores armados. A partir de esta situación se plantea la siguiente pregunta: ¿Cuáles son los factores que llevan a los civiles a favorecer la decisión de fundar una iniciativa de resistencia pacífica en una región en conflicto? La investigación sobre la Comunidad de Paz de San José de Apartadó nos dará algunas luces para aclarar esta cuestión.

Con el fin de responder a esta pregunta es decisivo saber de qué manera se concibe el contexto inmediato, es decir el conflicto armado, y qué capacidad de decisión le será atribuida a la población civil en el mismo. Guerra y paz no serán concebidos aquí como estados opuestos mutuamente excluyentes, sino que serán entendidos más bien como parte de procesos sociales. Aún durante un conflicto armado en el cual el acto de violencia es el elemento dominante, todas las demás dimensiones de la convivencia, como lo político, lo económico y lo cultural, siguen teniendo lugar (Lubkemann, 2008). Según Richards la guerra y la paz son modos rivales y congruentes de la existencia, que no están determinados temporalmente sino que se establecen a lo largo de un continuo (Richards, 2005). Para entender la dinámica del conflicto local, de sus expresiones específicas, así como de los comportamientos de la población civil y sus decisiones, es necesario considerar los procesos socio-históricos que trascienden el espacio de tiempo en que se da el ejercicio concreto de la violencia entre los actores armados.

En este contexto es decisivo además saber que tanta capacidad de acción es atribuida a la población civil en medio de conflictos violentos. Especialmente en publicaciones de Organizaciones de Derechos Humanos (p. ej. Amnistía Internacional, 2008) y de periodistas, los civiles son concebidos principalmente como víctimas pasivas (Bonacker, 2013; Lubkemann, 2008). Ese discurso victimizante priva implícitamente a los civiles de una actitud activa frente a su situación, y solo tematiza posibilidades de acción que tienen que ver con la imagen de víctima, como por ejemplo la colaboración forzada o el desplazamiento forzado. Con esa visión, se pasa por alto el hecho de que frecuentemente la colaboración surge como una decisión consciente que corresponde a una motivación interna para la acción por parte del colaborador, el cual actúa con conocimiento y agencia (Löfving, 2005). No obstante, incluso en el desplazamiento forzado puede notarse un margen de acción frente al mismo, cuando por ejemplo, se toma la decisión de abandonar la región, de establecer el sitio final de la huida, de organizar la huida misma e instalarse y llevar una vida en el sitio de llegada. Damos por sentado que a los civiles - a pesar de la imposición externa y del dolor sufrido en cuanto víctimas indiscutibles de los actores violentos-, les queda un cierto margen de poder para actuar que los convierte en actores activos en medio de una situación social difícil.

12 En Colombia, según datos de la Oficina de Derechos Humanos de la ONU (UNHCR), más de cinco millones de personas han sido desplazadas. 
¿Entonces, por qué unos civiles apuestan por una posición independiente y neutral en medio de la confrontación violenta? Se trata de una posibilidad de acción que en nada corresponde con los intereses de los actores violentos. Generalmente los grupos armados esperan tomar partido, puesto que el apoyo físico de la población civil a una de las partes puede significar la victoria, y sería visto como una toma de decisión para estar del lado de la verdad, el derecho y la moral (Robben, 2004). Bauman (1990) argumenta que a los ojos de los actores violentos no debe existir una posición neutral, puesto que una tercera posición cuestionaría no sólo la oposición dada, sino el principio mismo de la oposición, la plausibilidad de la dicotomía; y con esto se destruiría el orden del mundo vital del actor armado. Teniendo en cuenta lo anterior vamos a mostrar que con respecto a la Comunidad de Paz de San José de Apartadó, los procesos socio-históricos de larga duración caracterizados por la ausencia estatal por un lado, y las experiencias de la población civil en cuanto a auto-organización política y económica por otro lado, son factores que favorecen su creación. El juego conjunto de ambos factores, separados solo analíticamente ${ }^{13}$, conduce a una amplia autonomía local frente a las estructuras estatales.

\section{1.'La Violencia' y sus consecuencias}

El proceso socio-histórico que llevó a la fundación del poblado San José de Apartadó tiene que ver con la tradición de la violencia política en Colombia. La zona rural de Apartadó fue colonizada en los años 50 y 60 por personas que durante la guerra civil de 'La Violencia' (1948-1953) habían huido de otras regiones. El campesino E., líder y habitante de la Comunidad, que llegó siendo un niño junto con sus padres a la zona, cuenta:

La gente de esta zona ha sido procedente del municipio de Dabeiba y del municipio de Peque. Entonces la gente se iba uniendo porque era gente que se conocía desde allá, que traían también problemas y dificultades de la guerra del cuarenta y ocho. $\mathrm{O}$ sea, cuando viene la posguerra del cuarenta y ocho mucha gente se trasladaba a la zona de Urabá. (Entrevista, San José de Apartadó, 2008)

La mayoría de estas personas eran seguidores del partido liberal que buscaban protección de los ataques violentos por parte de los conservadores (Hernández Delgado, 2004: 377). Durante la huida, la gente compartió la experiencia común de la migración en cuanto a la pérdida de su hogar y de tener que comenzar de nuevo. La llegada al nuevo territorio se asoció con la esperanza de una vida a salvo y la seguridad de conseguir sustento económico, cuyos efectos identificador y unificador fomentaron el desarrollo de una fuerte cohesión social.

\subsection{Auto-organización del poblado}

Al principio, las condiciones ambientales de la zona colonizada fueron poco apropiadas para el asentamiento de la gente. Los colonizadores vivían debajo de lonas en medio del bosque y se alimentaban de plantas silvestres, de peces y cacería. Los

13 Con la distinción de estos dos factores se busca entender las condiciones de creación de estas iniciativas de resistencia tanto desde un enfoque estructural como desde el de los actores. 
productos básicos y los materiales de construcción eran cargados en la espalda desde Apartadó, la ciudad más próxima, a doce horas de distancia a pié en esa época por falta de carreteras (Lanchero, 2002: 44). La preparación de los terrenos para el cultivo requirió esfuerzos muy grandes debido a la exuberancia de la flora del territorio - que es una zona muy lluviosa. El campesino E. recuerda:

Desde que la gente entra allá como colonos a esta zona ha habido como toda esa relación de solidaridad entre todos los campesinos. Entonces era cuando se juntaban cien, doscientas personas a tumbar monte a hacha y así se rotaban en todas las fincas. (Entrevista, San José de Apartadó, 2008)

Un nuevo comienzo socioeconómico exigió una gran capacidad de organización colectiva de la población y relaciones solidarias entre los habitantes.

\subsection{La ausencia estatal}

Esta habilidad organizativa de la población fue necesaria para el desarrollo local, incluso por un largo periodo, dado que, salvo las pocas patrullas militares, en esta zona rural no ha habido una presencia constante por parte de las instituciones estatales. Esto quiere decir que el Estado no inició la construcción de una infraestructura social (caminos, escuelas, puestos de salud), tampoco organizó una administración pública, ni estableció un orden público (Ramírez Tobón, 1997: 71-80). Sin ir más lejos, como resultado de la ausencia estatal ${ }^{14}$, la guerrilla de las FARC hizo presencia desde los años 60 en esta zona rural, antes de establecer el $5^{\circ}$ Frente en 1973 (Ortiz Sarmiento, 1998: 141). Con su presencia sustituyó en cierta medida al Estado, por cuanto hizo valer unas reglas de convivencia y un orden público, o intermedió en conflictos entre los habitantes de la zona. La relación población — guerrilla era según la campesina M. de tal forma:

Cuando eran problemas muy graves la autoridad era la guerrilla y nosotros no lo podemos negar. La autoridad era la guerrilla, ya. Si eran problemas que no tenían solución entonces ahí mismo acudían ellos. Eran la autoridad en la zona. Entonces ya ellos arreglaban el problema, hablan con ellos y bueno, y se arreglaban. (Entrevista, San José de Apartadó, 2008)

Así quisieran o no, los pobladores tuvieron que adaptarse a la presencia de la guerrilla debido a la ausencia del Estado.

\subsection{EI desarrollo autónomo}

Después de que el pueblo de San José de Apartadó fuera fundado oficialmente en 1970, se dio vida a las 'Juntas de Acción Comunal'. Con ello se creó un espacio político que estimuló el desarrollo de la comunidad, y en el cual, con gran participación

\footnotetext{
14 Aquí nos referimos solo a la parte rural de Apartadó. La presencia estatal en el eje bananero fue más compleja. Por un lado, había un aporte estatal al sector agropecuario a través de créditos y la reducción de impuestos. Por otro lado, no se hacían esfuerzos para establecer normas en la mejora de las condiciones laborales en el mismo sector, ni para mejorar las condiciones de vida de la población (Ramírez Tobón, 1997).
} 
de los habitantes, se realizaron proyectos de mejoramiento de las condiciones de vida en la zona (Hernández Delgado y Salazar Posada, 1999: 62). El desarrollo económico se estimuló a través de la fundación de la cooperativa 'Balsamar' en el año 1976. La cooperativa se trazó como objetivos resolver los problemas de comercialización y elaboración de los productos cultivados, y apoyar a los campesinos mediante créditos e infraestructura. Como consecuencia de estas iniciativas de organización campesina se construyó la base de una infraestructura social y las condiciones de vida fueron mejorando continuamente (Hernández Delgado, 2004: 378).

\subsection{La persecución militar}

Con la llegada de los militares a la zona se dieron continuamente atropellos contra los civiles a quienes se acusaba de colaborar con la guerrilla. Ya en el año 1977 doce campesinos fueron tomados prisioneros por una patrulla del ejército, durante dos semanas fueron torturados y finalmente asesinados (Lanchero, 2002: 45). La persecución contra la población por parte de las fuerzas de seguridad estatales empeoró en el curso de los años 80, durante el tiempo en que se instalaba en la zona la 'Unión Patriótica'. Este partido político se posicionó a favor del desarrollo del campo, por lo cual consiguió pronto buenos resultados electorales, pero a la vez se convirtió en una amenaza para los dos partidos establecidos. Las relaciones de los habitantes en esta zona con las instituciones estatales estuvieron y siguen aún marcadas por desconfianza, precaución y reserva. El Estado nunca fue percibido como promotor de bienestar o protector, sino más bien como represivo:

No solo la Comunidad hemos sido masacrados. Son miles y miles de muertos en Colombia, millones de desplazados, gente exiliada. Y todo permanece en la total impunidad. Lo peor es que se mantienen atacando a la población civil común y corriente, o sea es un Estado criminal. Entonces nosotros no podemos reconocer y legitimar eso. Por eso, nosotros decimos: cuando el Estado haga justicia para todos estos miles de crímenes que se han cometido en Colombia, que el Estado muestre justicia, volveremos a creer en el Estado. (Entrevista, San José de Apartadó, 2008)

La explicación del campesino E., quien fue desplazado varias veces de su vereda, confirma que la población de San José de Apartado no es el único caso de abandono estatal en el territorio colombiano.

\subsection{Alejamiento y oposición}

La persecución militar descrita tuvo como consecuencia que la población en esta zona no viera en el Estado a un aliado de sus intereses. Muchos habitantes de la zona vieron a la 'Unión Patriótica' como una opción de organizarse políticamente y de impulsar el desarrollo del campo ${ }^{15}$. La creciente aprobación en la población (Ortiz Sarmiento, 1998: 73), y con ello el aumento del poder de ese partido, desencadenó su persecución y finalmente un proceso histórico único de exterminio

15 En los años 80 dos habitantes de San José de Apartadó representaron a la Unión Patriótica en el Consejo de Apartadó y uno en la Asamblea de Antioquia (Hernández Delgado y Salazar Posada, 1999: 62-63). 
del mismo ${ }^{16}$. Ante la violenta erradicación de la 'Unión Patriótica', representante de intereses rurales y oposición política frente a las estructuras de dominio estatal, los habitantes de San José de Apartadó confirmaron en forma aún más extrema las experiencias previas que habían tenido con el Estado. Sobre la reacción violenta de las instituciones estatales contra los campesinos, o en general contra aquellos que se organizaron en oposición a los intereses de quienes constituyen el Estado ${ }^{17}$, señala el campesino J.:

En una tierra tan productiva, el campesinado teniendo salud y teniendo educación, vías de penetración y electrificación no necesitaba absolutamente más nada. Pues al exigirle eso al Estado colombiano, fue que lo trajo como a la persecución de nosotros. [...] Eso ha sido una situación muy complicada. O sea, se ha vivido el campesino en un abandono total del Estado, en una discriminación por parte del Estado. Como decía, lo que hemos conocido por parte del Estado son los atropellos, todas las violaciones que se han cometido contra los campesinos. (Entrevista, San José de Apartadó, 2008)

Estas experiencias condujeron a la población a una creciente politización, a una progresiva actitud crítica contra el Estado y a una pérdida de confianza total en el mismo. Con ello, cobró aún mayor significado la opción de organizarse política y económicamente. Los procesos socio-económicos y las experiencias auto-organizativas aquí descritas se extendieron a lo largo de un lapso de cincuenta años, hasta que a mediados de los años 90 se llegó a una escalada de violencia, cuando grupos paramilitares penetraron en la zona para acabar con el dominio de la guerrilla. A raíz de esto, el pueblo de San José de Apartadó se declaró Comunidad de Paz.

Algunos trabajos de investigación sobre la conformación de estas iniciativas de resistencia reducen su inicio a circunstancias ahistóricas, singulares e inmediatas (Mitchell y Ramirez, 2009; Rojas, 2004). Mitchell y Ramírez explican la creación de esta Comunidad de Paz, primero a raíz del aumento de una amenaza externa poco concretizada; segundo por un acontecimiento decisivo poco definido, y tercero por una voluntad difusa de cambio (Mitchell y Ramírez, 2009: 266). Aparicio, de forma muy abstracta, relaciona la formación de la Comunidad de Paz con el desplazamiento o más exactamente con "la primera legislación oficial sobre los desplazados internos en Colombia" (2012: 4), la ley 387 de 1997. Según Aparicio (2012), la Comunidad de Paz con sus estructuras, sus prácticas y su cotidianidad defiende una concepción particular del ser humano, contraponiéndose así a una imposición vertical del Estado que busca controlar a la población desplazada a través de programas humanitarios. De manera más específica que Mitchell y Ramírez y más concreta que Aparicio, nosotros nos basamos más bien en procesos socio-históricos de larga duración, que se caracterizan en particular por la ausencia estatal, y en un alto grado de experiencia auto-organizativa de la población, como factores decisivos que favorecen la conformación de estas iniciativas de paz.

16 En ese ‘particidio’ fueron asesinados entre 1500 y 5000 miembros de este partido (Zelik, 1999: 67).

17 Otro caso emblemático es el sindicalismo en Colombia, que experimenta constantemente amenazas y represión (Amnistía Internacional, 2007). 


\section{El uso analítico del concepto de 'resistencia'}

Resistencia es un concepto amplio que aparece frecuentemente en las ciencias humanas y sociales; sin embargo, no es de extrañar que se carezca de una aclaración precisa del término. Tan omnipresente es el tema de la resistencia como volátil el uso del concepto (Brown, 1996:729; Sahlins, 2002: 23). Prácticamente cada fenómeno cultural o social puede ser reinterpretado como ejemplo de resistencia - por ejemplo el peinado (Kuumba \& Ajanaku, 1998; Weitz, 2001), el deporte (Carrington, 1998; Rowe, 1998; Sudgen \& Tomlinson, 1998; Tomlinson, 1998), el trabajo (May, 1999; Tucker, 1993), el humor (Griffiths, 1998) o la telenovela (M. E. Brown, 1994), algo que Sahlins llama una "hyper-inflation of significance [...] [that translates] the apparently trivial into the fatefully political" (Sahlins 2002, 23). El peligro de ese uso inflacionario es claro: resistencia, como categoría analítica pierde precisión y significado. El término se vuelve trivial y polisémico, con lo que su aplicación científica se dificulta (Brown, 1996: 729).

Dentro de la antropología existe, por un parte, una variedad de trabajos que analizan aspectos específicos de diferentes resistencias, sus expresiones locales y sus transformaciones, a partir de contextos concretos tanto históricos, sociales, políticos como culturales (p.ej. Abu-Lughod, 1990; M. F. Brown, 1996; Comaroff, 1985; Kaplan \& Kelly, 1994; Starn, 1995). Estos trabajos muy pocas veces se ocupan de profundizar analíticamente el concepto de resistencia en términos generales más allá de su propia aplicación. Por otra parte, existen conceptos como la 'resistencia cotidiana' (1987) o el 'hidden transcript' (1990) de James Scott, que generalizan estrategias y prácticas de grupos relativamente impotentes y que fueron usados casi excesivamente para el análisis de fenómenos muy distintos (hasta tribunales militares, vea p.ej. Greenhouse, 2005), de manera que estos conceptos también perdieron su precisión analítica. La 'resistencia legítima' de O'Brien (1996), quien como James Scott proviene de los estudios campesinos, tampoco ofrece mucho a la hora de aclarar el uso analítico de resistencia como categoría. Sin embargo, esta forma de resistencia, que se basa en el uso creativo de leyes y valores de una sociedad para desafiar la arbitrariedad y el abuso del poder de élites políticas y económicas, nos parece apto para una reflexión teórica del caso de la Comunidad de Paz. Al respecto profundizaremos en el apartado 6.

A pesar de lo mencionado anteriormente, ¿por qué no debe ser descartada la resistencia como concepto analítico? Al revisar varios cientos de publicaciones sobre el tema de la resistencia, los sociólogos Hollander y Einwohner identifican elementos y dimensiones que pueden ayudar a definir el concepto analíticamente, o sea operacionalizarlo. Basándonos en su revisión, los autores consideran los elementos de una 'actitud opositora' y una 'conducta activa' como constitutivos para que un comportamiento se pueda clasificar como resistencia (Hollander y Einwohner, 2004: 538). Además, distinguen una serie de dimensiones de resistencia tales como el objetivo, la extensión, la intensión, el reconocimiento, el modo de proceder y el objeto, las cuales son tratadas (no siempre todas) en la literatura revisada por ellos (Hollander y Einwohner, 2004: 535-544). Nosotros tomamos estos dos elementos básicos y las dimensiones mencionadas como punto de partida para una operacionalización del concepto de resistencia. Creemos que con una descripción etnográfica de las dimensiones particulares de la Comunidad de Paz se consigue un primer acercamiento analítico, que más adelante se contrapone con el concepto teórico de la 'resistencia legítima' de O’Brien (1996). 


\section{La resistencia de la Comunidad de Paz}

¿Es la Comunidad de Paz de San José de Apartadó un proyecto de resistencia? De ser así, ¿contra quién se dirige?, ¿con qué objetivos? y ¿cómo se manifiesta su resistencia? En lo que sigue, vamos a analizar brevemente la resistencia de esta Comunidad de Paz aplicando las dimensiones ya mencionadas de Hollander y Einwohner, es decir, haciendo referencia a sus objetivos, su extensión, su intención, su reconocimiento, su modo de proceder y su objeto (2004: 536-542).

Según su declaración del 23 de marzo de 1997 la Comunidad de Paz "se define como aquella que hace parte de la población civil campesina, no combatiente" (CdP San José de Apartadó; 1997a: Art. 2). En detalle eso significa, que:

Las personas que hacen parte [...] se comprometen a no participar directa ni indirectamente en las hostilidades [...], se abstienen de portar y/o tener armas, municiones o materiales explosivos, $[\ldots]$ se abstienen de brindar apoyo logístico a las partes en conflicto, $[\ldots]$ y se abstienen de acudir a alguna de las partes en conflicto para solucionar problemas internos, personales o familiares. (CdP San José de Apartadó, 1997a: Art. 3)

La comunidad cuenta con un Consejo Interno conformado por ocho personas quienes deberán ser elegidos regular y oportunamente y que cumplirá funciones administrativas y representativas (CdP San José de Apartadó, 1997a: Art. 7). Otras instituciones que permiten y requieren la participación de los miembros son los comités (por ejemplo, de salud y educación), la coordinación de las veredas y la Asamblea General. La base económica de la Comunidad está compuesta por los grupos de trabajo: la unidad de producción no es la familia sino estos grupos de trabajo que están conformados por personas de diferentes familias. Con esta interdependencia económica de diferentes familias se quiere construir comunidad desde lo cotidiano, que es el trabajo del campo (CdP San José de Apartadó, s.f.: 23). Además existen trabajos comunitarios que aseguran la subsistencia y la seguridad alimentaria (CdP San José de Apartadó, s.f.: 23-25), cuyo papel es crucial en el contexto de la Comunidad, como explica la campesina M.: "Entonces la seguridad de nosotros está en la seguridad alimentaria. Si nosotros tenemos comida, tenemos fuerza de resistencia." (Entrevista, San José de Apartadó, 2008)

Los objetivos de la resistencia de la Comunidad de Paz pueden resumirse en tres puntos: (1) los actores armados legales e ilegales deben respetar el estatus de los habitantes de la comunidad de paz en cuanto población civil, y no violar Derechos Ciudadanos garantizados constitucionalmente, los Derechos Humanos ni el Derecho Internacional Humanitario (CdP San José de Apartadó, 1997a: Art. 2). (2) Los habitantes exigen una relación con los actores armados y con el Estado que permita una vida digna y plena en su tierra, sin el peligro potencial o real de ser objeto de un desplazamiento. Al respecto enfatiza el campesino J.: "Firmamos la declaratoria con el ánimo de que nos iban a respetar. Y que íbamos a poder mantener las tierras porque la lucha de nosotros acá es cómo poder mantener el campesinado, que no sean desplazados" (Entrevista, San José de Apartadó, 2008). (3) La Comunidad exige justicia frente a los crímenes contra ella y sus habitantes, sean estos cometidos por la guerrilla, los grupos paramilitares o las fuerzas militares del Estado colombiano (Hernández Delgado, 2004: 384). 
La extensión directa de esta resistencia no va más allá de los límites regionales. Las relaciones de solidaridad crecientes con organizaciones nacionales e internacionales no gubernamentales y con organizaciones de Derechos Humanos ${ }^{18}$ incrementan sin embargo la extensión indirecta de esta resistencia y su función de ejemplo para otros pueblos. Después de la Comunidad de Paz de San José de Apartadó, según distintas fuentes, se han creado entre quince y cincuenta y nueve de estas comunidades de paz (la Comunidad misma cuenta quince; Cuartas, 2007: 31 cuenta 52; y Sandford 2004: 248 informa de 59).

La intención consciente de la Comunidad de Paz de oponer resistencia se manifiesta en el proceso colectivo, auto-determinado y democrático de organización (CdP San José de Apartadó, 1997b), que precede a las decisiones de la Asamblea General sobre acciones y estrategias de auto-protección, que detallaremos más adelante en el modo de proceder.

El reconocimiento de la resistencia depende de su visibilidad y de su percepción por parte de los involucrados en el conflicto armado, y por parte de terceros que permanecen por fuera (Hollander y Einwohner, 2004: 540). Al contrario de la 'resistencia cotidiana" ${ }^{19}$, que evita una confrontación abierta, la Comunidad de Paz no tiene ningún interés en esconder su resistencia. El reconocimiento de la resistencia se evidencia a través de los atropellos violentos por parte de los actores armados y en las medidas estatales contra la Comunidad (procesos jurídicos, propaganda mediática etc.). Las relaciones con organizaciones internacionales, sentencias de la Corte Interamericana de Derechos Humanos, y las distinciones internacionale ${ }^{20}$ son pruebas de que esta resistencia también obtiene reconocimiento por parte de terceros.

El modo de proceder de la resistencia para el caso de la Comunidad de Paz de San José de Apartadó es pacífico, puesto que el uso de la violencia y la posesión de armas están prohibidos (CdP San José de Apartadó, 1997a: Art. 3). Finalmente, las acciones opositoras se pueden subdividir en: acciones activas, abstención de actuar y acciones de resistencia cotidiana.

Las acciones activas de resistencia se manifiestan en diversos campos: sociales, jurídicos y simbólicos. Directamente en el territorio de la comunidad se llevan a cabo: la organización de una estructura política participativa con Consejo Interno, Asamblea General y diversos comités, así como una economía solidaria con grupos de trabajo y trabajo comunitario. Indirectamente, se tramitan demandas ante la Corte Interamericana de Derechos Humanos para llamar la atención sobre los crímenes cometidos y obtener sanciones jurídicas para los actores violentos (Mijangos y González, 2007). Las acciones simbólicas incluyen, por ejemplo, la retirada de los miembros de la Comunidad hacia sus propias tierras, que han cercado y señalizado con avisos, en los cuales limitan el ingreso y la salida, donde han puesto su propia bandera, y para las cuales han compuesto su propio himno. Gloria Cuartas, unas de las destacadas defensoras de Derechos Humanos de Colombia, entiende esa manera

18 Por ejemplo, CINEP, Amnistía Internacional o el Comité Internacional de la Cruz Roja.

19 Scott define la 'resistencia cotidiana' como: "the ordinary weapons of relatively powerless groups: foot dragging, dissimulation, desertion, false compliance, pilfering, feigned ignorance, slander, arson, sabotage [...] They require little or no planning; they make use of implicit understandings and informal networks; they often represent a form of individual self-help; they typically avoid any direct, symbolic confrontation with authority" (Scott, 1985: xvi).

20 A esta iniciativa de paz le fue otorgado en el año 2007 el Premio de Paz de la ciudad de Aachen (Alemania) y la nominación para el premio nobel de Paz. 
de proceder como una forma de expresar las distinciones éticas de la Comunidad misma enfrente a los actores armados:

El hecho, por ejemplo, de advertir que no vive simbólicamente en este país, que no se comparte el mismo territorio con los armados es una simbólica [sic] que no la ha hecho ninguna comunidad, ni la indígena, en Colombia, nadie. Porque ellos le dicen al ejército y la policía: su simbólica [sic] es de represión, su simbólica [sic] es de ruptura y nosotros asumimos otro lugar. (Entrevista, Bogotá, 2008)

Finalmente, se ha establecido una práctica y un simbolismo de la memoria, que según el habitante E. cobra mayor importancia:

También es eso, recoger lo de la memoria histórica. Es una de las luchas de la comunidad, mantener la historia viva. Porque el ser humano que olvida su historia está perdido. Pues porque seguirá viviendo lo mismo sin poder hacer nada, o ante las injusticias no va a hacer nada. ¡Sí! El trabajo de la memoria es bien importante. (Entrevista, San José de Apartadó, 2008)

Este trabajo se expresa en la conmemoración de aniversarios, por ejemplo, de la comunidad o de masacres, y en la construcción de un monumento hecho con piedras para las víctimas. La integración de la solidaridad internacional en estrategias locales es obviamente una forma muy eficaz de autoprotección para la resistencia de la Comunidad $^{21}$.

Abstenerse de actuar puede también ser un acto de resistencia, como puede verse de manera más clara a través de la abstención de colaborar con los actores armados. En cuanto ninguna información debe transmitirse, ningún apoyo logístico debe aceptarse, los actores armados dejarán de ser reconocidos perdiendo así esa base tan importante para su existencia local (CdP San José de Apartadó, 1997a: Art. 3). La no-colaboración con los actores armados es una de las acciones más eficaces de resistencia, puesto que a través de ella la oposición binaria de los actores se quiebra y la constitución de una tercera posición en la constelación del conflicto local se hace posible (Bauman, 1990). La abstención de participar en las elecciones y en el servicio militar obligatorio son otras acciones de alta importancia para la Comunidad, como explica el campesino J.:

La comunidad no presta servicio militar. Y cualquier joven que se ha cogido para prestar servicio militar, la comunidad lo saca. Si él toma la decisión de pagar servicio, pues bueno, ya es otra cosa. Deja su comunidad y ya es decisión de él. Pero la comunidad no presta servicio militar. (Entrevista, San José de Apartadó, 2008)

Acciones cotidianas que a causa de la situación de amenaza se convierten en una acción de resistencia son por ejemplo los trabajos colectivos en el campo, a pesar de la amenaza de represión por parte de los actores armados. En una situación de peligro concreta, por ejemplo cuando los miembros de la Comunidad se encuentran

21 La Comunidad cuenta con el acompañamiento de tres organizaciones internacionales que son las Brigadas Internacionales de Paz, el Fellowship of Reconciliation y las Palomas. 
con soldados, guardan silencio, aparentan no saber nada o engañan; comportamientos que coinciden con los descritos en la 'resistencia cotidiana' de Scott (1985: xvi). De igual manera se observa un reforzamiento simbólico y discursivo de la propia resistencia en la Comunidad de Paz a través de una variedad de canciones, poesías, anécdotas y chistes que tematizan la experiencia de la resistencia, (Scott, 1990: 184).

Con respecto al objeto, cabe señalar una cierta correlación con las causas del conflicto mencionado anteriormente. La Comunidad de Paz resiste a la lógica y la praxis militar de los actores armados, puesto que a través de su neutralidad esquiva el esquema binario amigo-enemigo, no se deja involucrar en la confrontación armada y reconstituye la posición de la población civil (Valenzuela, 2010). Estas actividades también van contra la lógica y la praxis política del Estado colombiano, que consisten entre otras en clientelismo, corrupción, compra de votos ${ }^{22}$ y como se ha mencionado antes, en la exclusión histórica de la población en la construcción de proyectos políticos (Guillén Martínez, 2004). El proceso organizativo de la Comunidad de Paz se basa por el contrario en participación, diversidad de opiniones y en un diálogo que apoye las decisiones democráticas. Frente a la existente marginación de los campesinos, la Comunidad contrapone una forma de economía local que se orienta hacia la solidaridad campesina y la seguridad alimentaria. Con la coordinación de proyectos económicos, los grupos de trabajo y los trabajos comunitarios, la comunidad se vuelve contra la lógica y la praxis económica de Colombia, que es fuertemente neoliberal.

Teniendo en cuenta que la Comunidad de Paz de San José de Apartadó es entonces una forma de resistencia extremadamente compleja y ligada al contexto, ¿de qué manera se podría hacer una reflexión teórica acerca de esta forma de resistencia?

\section{Una reflexión del concepto 'resistencia legítima'}

Al revisar los tipos de resistencia clasificados en la literatura científica se observa que dicha clasificación permanece relacionada a alguna de las denominadas dimensiones de la resistencia: modo de proceder, extensión, objeto, intensión, reconocimiento y objetivo. Sin embargo, la mayoría de las veces el principio de clasificación correspondiente no es evidente. Este modo de diferenciación permite una cierta sistematización de los distintos fenómenos que pueden ser designados como resistencia; sin embargo, su función analítica con vista a la explicación teórica de la resistencia parece limitada. A continuación queremos comentar brevemente las clasificaciones con respecto al modo de proceder, desarrollar una propuesta de sistematización en línea con los objetivos y proponer una explicación teórica de la resistencia de la Comunidad de Paz.

Según el modo de proceder, es decir la forma en que las acciones de la resistencia se llevan a cabo, la literatura especializada distingue un gran número de resistencias, que de entrada se separan entre violentas ${ }^{23}$ y pacíficas. Las resistencias pacíficas se

22 El escándalo de las 'chuzadas' - la interceptación de teléfonos de políticos de la oposición- por el DAS (Departamento Administrativo de Seguridad) del año 2009; la compra de votos para la reforma constitucional que permitió la reelección presidencial en el año 2006; o las estrechas relaciones entre reconocidos paramilitares y políticos son solo algunos ejemplos recientes de estas prácticas.

23 Para discusiones científicas recientes sobre movimientos de resistencia violentos y revoluciones, ver Goldstone (2003) y Wickham-Crowley (1993). 
diferencian entre 'resistencia no-violenta por principio' y 'resistencia no-violenta pragmática'. La 'resistencia no-violenta por principio' se basa en convicciones religiosas, ideológicas o filosóficas, y se remonta a los escritos y los logros de Gandhi (1950), que son reelaborados entre otros por Bondurant (1988) y Gregg (1965). La 'resistencia no-violenta pragmática' (también llamada acción no-violenta o directa) lleva la dimensión estratégica de la no-violencia al centro del análisis, y se basa en las reflexiones de Sharp (1973), que en la actualidad son reelaboradas entre otros por Ackerman y Rodal (2008). Aunque ambos enfoques son muy influyentes, bastante discutidos y en muchos casos pueden ser muy productivos, tematizan principalmente movimientos políticos de extensión nacional e ignoran los pequeños proyectos de resistencia o las formas de resistencia cotidiana (Dudouet, 2008). Por ello su potencial explicativo frente a la Comunidad de Paz es limitado.

La no-violencia de la Comunidad de Paz no se puede ubicar a partir de una convicción constituida por predisposición, sino más bien proviene en primer término de una experiencia directa con la violencia. Sin embargo, una reducción de la no-violencia a su potencial estratégico sería una simplificación de la historia, la experiencia y la situación compleja en la que los miembros de la Comunidad de Paz desarrollan su resistencia. Junto a estos enfoques, también pertenecen al modo de proceder las estrategias de la 'resistencia cotidiana' (Scott, 1985) o las formas simbólicas de resistencia (Scott, 1990), que como antes se ha descrito pueden sustentar en parte el concepto de resistencia de la Comunidad de Paz.

En vez de clasificar la resistencia de la Comunidad de Paz por su modo de proceder, lo cual no nos parece conveniente ya que sus estrategias y prácticas son demasiado diversas para asignarlas a un solo concepto, nos parece más interesante pensar en una clasificación teórica desde la perspectiva de sus objetivos. Por lo tanto, queremos avanzar hacia una distinción de resistencias a partir de dos dimensiones en cuanto a los objetivos: la existente o ausente aspiración de dominación política y la meta de superar el orden normativo existente, reformándolo o también aplicándolo de facto.

A las formas de resistencia que plantean una aspiración de dominación política pertenecen muchas variantes de los movimientos de oposición política (p.ej. Stephan y Chenoweth, 2008); desde movimientos de independencia y movimientos guerrilleros armados (p.ej. Pizarro Leongómez, 1996), hasta los movimientos revolucionarios clásicos de Francia y Rusia (p.ej. Skocpol, 2006). Cuando la aspiración de dominio no se dirige a la totalidad de un Estado, puede tratarse de la construcción de un espacio autónomo (p.ej. territorios indígenas o legislaciones autónomas, ver Churchill, 1993), o puede tratarse incluso de metas separatistas (p.ej. Shaykhutdinov, 2010). También existen definitivamente, formas de resistencia sin aspiración de dominio político. En esos casos se trata frecuentemente de resistencia para imponer intereses particulares como la lucha laboral organizada sindicalmente (p.ej. Uba, 2008), las protestas estudiantiles (p.ej., Kuri 2003), o formas de resistencia contra la energía atómica (p.ej. Roose, 2010).

La resistencia puede también diferenciarse con respecto a su relación con el orden normativo ${ }^{24}$. La meta de cambiar el orden normativo imperante puede incluir

24 Por ordenamiento normativo se denomina al complejo de normas y valores con los cuales la estructura de una sociedad y en especial el ejercicio de la dominación será legitimado. Estas normas no constan exclusivamente de normas jurídicas explícitas, sino son una red de normas jurídicas, económicas, morales, éticas y pragmáticas, culturales y religiosas (Forst y Klaus, 2010). 
desde aspiraciones políticas reformistas (p.ej. autonomía) hasta la sustitución del sistema político (p.ej. revoluciones). Que la aspiración de dominación política no tiene que estar acompañada por el cambio del orden político normativo, se puede ver en varios movimientos de oposición política, o en parte también en los resultados de las 'revoluciones de color' en Europa Oriental25. Por otro lado, formas de resistencia que no tienen aspiración de dominio político pueden tener definitivamente como meta el cambio del orden normativo, especialmente en lo moral o lo sociocultural, como es el caso de movimientos feministas o LGBT (p.ej. Novkov y Barclay, 2010).

Cuadro de ejemplos de resistencias según su objetivo:

\begin{tabular}{|l|l|l|}
\hline $\begin{array}{l}\text { Dominación política } \\
\text { Orden normativo }\end{array}$ & Con aspiración a ... & Sin aspiración a ... \\
\hline Cambiar el ... & $\begin{array}{l}\text { movimientos } \\
\text { revolucionarios }\end{array}$ & $\begin{array}{l}\text { movimientos } \\
\text { feministas/LGBT }\end{array}$ \\
\hline Reformar el ... & $\begin{array}{l}\text { movimientos de } \\
\text { autonomía }\end{array}$ & $\begin{array}{l}\text { movimiento sindical, } \\
\text { estudiantil, indígena }\end{array}$ \\
\hline Conservar el ... & $\begin{array}{l}\text { movimientos de } \\
\text { oposición }\end{array}$ & \\
\hline
\end{tabular}

Ahora bien, la cuestión es ¿puede existir una resistencia que no plantee ninguna aspiración de dominio político y cuya meta sea la aplicación, la puesta en vigencia de un orden normativo? Un ejemplo de este tipo de resistencia es la 'resistencia legítima' de O’Brien, quien describe las estrategias de la población rural de China para disponer de manera innovadora las leyes e instrucciones del Partido Comunista y resistir así la arbitrariedad de las élites políticas y económicas (O’Brien, 1996). En consecuencia, algunos campesinos chinos en contra de los dirigentes locales y corruptos se remiten a las directivas del Partido Comunista $-\mathrm{y}$ a las normas del mismo - para imponer sus intereses contra lo de los dirigentes locales, p. ej. para garantizarle a los campesinos las ventajas económicas a las que tienen derecho. $\mathrm{La}$ 'resistencia legítima' como ya hemos mencionado es una forma de resistencia "that (1) operates near the boundary of an authorized channel, (2) employs the rhetoric and commitments of the powerful to curb political or economic power, and (3) hinges on locating and exploiting division among the powerful." (O'Brien, 1996: 33).

La 'resistencia legítima' se basa en normas legales y formula la entrada en vigencia de estas como objetivo. La 'resistencia legítima' da así por sentado un orden práctico y formal existente, estatal u organizativo, con lo cual la resistencia es formulada con respecto a instrucciones y reglas existentes y con reconocimiento de las

25 Así, por ejemplo, el desencadenante de la revolución naranja en Ucrania en el 2004 fue el fraude electoral en las elecciones presidenciales; su resultado - la realización de nuevas elecciones - no cambió el orden normativo. 
mismas. ¿En qué medida se pueden trasladar estas formas de resistencia al caso de la Comunidad de Paz que aquí se investiga?

En primer lugar, se entiende que la Comunidad de Paz no tiene ninguna aspiración de dominación política, como tampoco pretende la sustitución del sistema político imperante. Aun cuando establezca nichos civiles en medio del conflicto, el objetivo de esta resistencia es el ejercicio de los derechos de la población civil que están escritos en el Derecho Internacional Humanitario, así como el respeto de los Derechos Humanos y Ciudadanos, garantizados constitucionalmente. Entonces, esta iniciativa tiene como objetivo el cumplimiento de un orden normativo existente que afecta al conjunto de la población y que se respalda en el sistema político basado en la Constitución, sin que por ello se pretenda alcanzar cargos políticos. Esta estrategia de exigir metas que desde un punto de vista normativo legal no puedan ser rechazadas, coincide en gran parte con la de 'resistencia legítima'.

A diferencia de la 'resistencia legítima' en el Estado centralista chino, que se ubica en el límite de la resistencia popular y la participación institucionalizada (O’Brien, 1996: 33), la estrategia de la Comunidad de Paz consiste por un lado en invocar normas reconocidas por el Estado, si bien por otro lado evita hasta donde sea posible la colaboración institucional con él, tal como con los otros actores armados. La ausencia de instituciones civiles estatales fomenta la construcción de la autoorganización de la resistencia de la Comunidad de Paz, y la abstención de cooperar con actores armados, estatales o no; es un recurso central de la resistencia.

La 'resistencia legítima' de los campesinos chinos es oportunista y mesurada. Casi nunca cuenta con recursos organizativos ni con la conciencia colectiva de los grupos bien organizados (O'Brien, 1996). Al contrario de ellos, la Comunidad de Paz se encuentra muy bien organizada, y este alto grado de organización es un requisito para que los civiles consigan resistir a los actores armados y a su lógica. Mientras que los 'resistentes legítimos' de China disminuyen el riesgo de la confrontación a través del anuncio de su fidelidad a los valores centrales, la Comunidad de Paz por su parte, si bien se afirma y apoya en derechos fundamentales que le corresponden a los civiles en situaciones de guerra que también son reconocidos por el Estado colombiano, de todas maneras se opone conscientemente a todos los actores armados en el terreno. Nos hemos ocupado de una forma específica de 'resistencia legítima' que no maneja la confianza oportunista ni la cercanía con el sistema, sino que se apoya en la exigencia normativa de derechos vigentes, en la neutralidad y en la nocooperación con ninguno de los actores armados. Para el caso investigado, la exigencia de derechos no significa lealtad, confianza, conformidad ni cercanía estratégica con el sistema político; por el contrario, demuestra el fracaso de este, y legitima de tal manera la no-cooperación. Ambas formas de resistencia comparten la necesidad de ser, en la medida de lo posible, visibles y conocidas, y se diferencian en ello de la 'resistencia cotidiana' (Scott, 1985).

La Comunidad de Paz no practica ninguna 'resistencia legítima' oportunista, puesto que ésta conduciría finalmente a colaborar y apoyar a los grupos armados, lo que difícilmente sería legítimo. Se trata más bien de una resistencia auto-administrada, que a través de la no-cooperación, o sea la neutralidad, consigue reactualizar una posición civil dentro del conflicto y reclamar unas normas legales existentes. Mientras que las raíces de la resistencia oportunista se sitúan en la política central de un Estado u organización poderosa (por ejemplo, China), las raíces de la resistencia auto-administrada y orientada normativamente se centra en la ausencia del Estado, 
y en normas internacionales que al menos formalmente también son asumidas por el mismo (por ejemplo, Colombia).

\section{Conclusiones}

En las páginas anteriores se examinaron las condiciones de conformación y la clasificación de iniciativas pacificas de resistencia civil en conflictos armados a partir de la Comunidad de Paz de San José de Apartadó en Colombia. Partiendo del supuesto de que la población civil en medio de conflictos armados constituye un actor autónomo, se pudo mostrar que procesos históricos de larga duración marcados por la ausencia del Estado, y un alto grado de experiencia de auto-organización de la población civil en campos políticos y económicos, favorecen la fundación y creación de semejantes iniciativas de resistencia pacífica civil. En particular, el análisis del modo de proceder con sus diversas acciones de resistencia mostró la complejidad organizativa de las estrategias aplicadas a la resistencia que no pueden ser entendidas utilizando conceptos teóricos conocidos, como el de 'resistencia cotidiana' de Scott (1985).

Teniendo en cuenta que la Comunidad de Paz no tiene ninguna pretensión de dominación política, en tanto que respeta la Constitución, por representar los intereses de la población civil, y como tiene la meta de hacer efectivas normas legales sobre los Derechos Humanos y el Derecho Internacional Humanitario, ha sido analizada aquí como una forma específica de 'resistencia legítima'. Con ello se puso en claro que se trata de una forma de 'resistencia legítima' no-oportunista, que permite descomponer el concepto de O'Brien y contraponerle a esa versión dosificada y oportunista de 'resistencia legítima', una versión normativa de resistencia basada en la neutralidad y en la evitación de los actores armados, que a la vez se consolida haciéndose pública y estando presente en procesos de instancias legales internacionales.

\section{Referencias bibliográficas}

Abu-Lughod, Lila (1990). "The Romance of Resistance: Tracing Transformations of Power through Bedouin Woman.” American Ethnologist, 17 (1): 41-55.

Ackermann, Peter; Rodal, Berel (2008). "The Strategic Dimensions of Civil Resistance." Survival, 50 (3): 111-26.

Amnistía Internacional (2007). Sindicalismo en Colombia. Homicidios, Detenciones Arbitrarias y Amenazas de Muerte. Madrid: Amnesty International Publications.

- (2008). “!Déjennos en Paz!” La Población civil, víctima del conflicto armado interno de Colombia. Madrid: Amnesty International Publications.

Aparicio, Juan R. (2012). Rumores, residuos y Estado en "la mejor esquina de Sudamérica". Una cartografía de lo "humanitario” en Colombia. Bogotá: Universidad de los Andes.

Bauman, Zygmunt (1990). "Modernity and Ambivalence.” en M. Featherstone (Ed.), Global Culture: Nationalism, Globalization, and Modernity. London: Sage, 143-169.

Bonacker, Thorsten (2013). "Global Victimhood: On the Charisma of the Victim in Transitional Justice Processes.” World Political Science Review, 9 (1): 97-129.

Bondurant, Joan Valerie (1988). Conquest of Violence: The Gandhian Philosophy of Conflict. Princeton: Princeton University Press. 
Bräuchler, Birgit (2015). The Cultural Dimension of Peace. Decentralization and Reconciliation in Indonesia. Basingstoke: Palgrave Macmillan.

Brown, Mary E. (1994). Soap Opera and Woman's Talk: The Pleasure of Resistance. Thousand Oaks, CA: Sage Publications.

Brown, Michael F. (1996). “On Resisting Resistance.” American Anthropologist, 98 (4): 72935.

Carrington, Ben (1998). "Sport, Masculinity, and Black Cultural Resistance." Journal of Sport \& Social Issues, 22 (3): 275-298.

CDP San José de Apartadó. s.f. San José de Apartadó - Caminos de Resistencia. Bogotá.

- (1997a). "Declaración Relativa a la Comunidad de Paz de San José de Apartadó." Comunidad de Paz de San José de Apartado. http://cdpsanjose.org/?q=/node/9 (Consultado el 13 de junio de 2014).

- (1997b). "Reglamento Interno de la Comunidad de Paz de San José de Apartadó." Comunidad de Paz de San José de Apartado. http://cdpsanjose.org/?q=/node/7 (Consultado el 13 de junio de 2014).

- (2009). "Constancias Históricas." Comunidad de Paz de San José de Apartado. http:// cdpsanjose.org/?q=/taxonomy/term/5 (Consultado el 13 de junio de 2014).

Churchill, Ward (1993). Struggle for the land: indigenous resistance to genocide, ecocide, and expropriation in contemporary North America. Monroe, Me.: Common Courage Press.

CINEP (1995). Urabá - Informe de la Comisión Verificadora de los Actores Violentos en Urabá. Bogotá: Ediciones Antropos.

Comaroff, Jean (1985). Body of power, spirit of resistance: the culture and history of a South African people. Chicago: University of Chicago Press.

Cuartas, Gloria (2007). Ante la impunidad y la indiferencia: la experiencia de memoria, verdad y vida de la Comunidad de Paz de San José de Apartadó. Bogotá: BPR Publishers.

Dudouet, Véronique (2008). "Nonviolent Resistance and Conflict Transformation in Power Asymmetries.” Berlin: Berghof Forschungszentrum für konstruktive Konfliktbearbeitung.

Forst, Rainer; Klaus, Günther (2010). "Die Herausbildung normativer Ordnungen.” Normative Orders Working Paper 1/2010. Frankfurt a.M.: Goethe-Universität Frankfurt a.M.

Gandhi, Mohandas K. (1950). Satyagraha in South Africa. Ahmedabad: Navajivan Publ. House.

Goldsonte, Jack A. (2003). "Comparative Historical Analysis and Knowledge Accumulation in the Study of Revolutions." en J. Mahoney, D. Rueschemeyer (Eds.), Comparative Historical Analysis in the Social Science. Cambridge: Cambridge University Press, 41-90.

Greenhouse, Carol J. (2005). "Hegemony and Hidden Transcripts: The Discursive Arts of Neoliberal Legitimation.” American Anthropologist, 107 (3): 356-368.

Gregg, Richard B. (1965). Die Macht der Gewaltlosigkeit. Bellnhausen: Verlag des Institutes für Geosoziologie und Politik.

Griffiths, Lesley. (1998). "Humor as resistance to professional dominance in community mental health teams." Sociology of Health \& Illness, 20 (6): 874-895.

Guillén Martínez, Fernando (2004) El poder político en Colombia. Bogotá: Editorial Planeta.

Heinz, Wolfgang S. (1997). "Die kolumbianische Verfassung.“ en W. Altmann, T. Fischer, K. Zimmermann (Eds.), Kolumbien heute: Politik, Wirtschaft, Kultur. Frankfurt am Main: Vervuert Verlag, 137-47.

Hernández Delgado, Esperanza; Salazar Posada, Marcela (1999). Con la esperanza intacta: Experiencias comunitarias de resistencia civil no violenta. Colombia: Oxfam-GB. 
Hernández Derlgado, Esperanza (2004). Resistencia civil artesana de paz. Experiencias indígenas, afrodescendientes y campesinas. Bogotá: Editorial Pontificia Universidad Javeriana.

Hollander, Jocelyn A.; Einwohner, Rachel L. (2004). "Conceptualising Resistance." Sociological Forum, 19 (4): 533-554.

Jellinek, Georg (1959). Allgemeine Staatslehre. Darmstadt: Wissenschaftliche Buchgesellschaft.

Kaplan, Martha; Kelly, John D. (1994). „Rethinking resistance: dialogics of „disaffection“ in colonial Fiji.“ American Ethnologist, 21 (1): 123-151.

Kuri, Ariel Rodríguez (2003). "Los primeros días. Una explicación de los orígenes inmediatos del movimiento estudiantil de 1968." Historia Mexicana, 53 (1): 179-228.

Kurtenbach, Sabine (2004). Gewalteindämmendes Engagement externer Akteure in Kolumbien. Hamburg: Institut f. Iberoamerika-Kunde.

Kuumba, M. Bahati.; Ajanaku, Femi (1998). "Dreadlocks: The Hair Aesthetics of Cultural Resistance and Collective Identity Formation." Mobilization: An International Quarterly, 3 (2): 227-243.

Lanchero, Eduar J. (2002). El Amanecer de las Resistencias. Bogotá: Editorial Códice LTDA.

Löfving, Stefan (2005). "Silence \& the Politics of Representing Rebellion. On the Emergence of the Neutral Maya in Guatemala." en P. Richards (Ed.), No Peace No War. An Anthropology of Contemporary Armed Conflicts. Athens: Ohio University Press, 77-97.

Lubkemann, Stephen (2008). Culture in Chaos. An Anthropology of the Social Condition in War. Chicago and London: University of Chicago Press.

May, Tim (1999). "From Banana Time to Just-in-Time: Power and Resistance at Work." Sociology, 33 (4): 767-783.

Mertins, Günther (2001). “Aktionsräume von Guerilla und paramilitärischen Organisationen: regionale und bevölkerungsgeographische Auswirkungen." en S. Kurtenbach (Ed.), Kolumbien zwischen Gewalteskalation und Friedenssuche. Möglichkeiten und Grenzen der Einflussnahme externer Akteure. Frankfurt am Main: Vervuert Verlag, 36-51.

Mijangos y González, Javier (2007). "La Doctrina de la Drittwirkung der Grundrechte en la Jurisprudencia de la Corte Interamericana de Derechos Humanos." Teoría y Realidad Constitucional, (20): 583-608.

Mitchell, Christopher; Ramirez, Sara (2009) "Local peace communities in Colombia: an initial comparison of three cases." en V.M. Bouvier (Ed.), Colombia: building peace in a time of war. Washington D.C.: United States Institute of Peace Press, 245-70.

Naucke, Philipp (2011). Der Stein im Schuh. Über friedlichen, zivilen Widerstand in gewaltsamen Konfliktregionen. Eine Fallstudie der Friedensgemeinde San José de Apartadó, Kolumbien. Marburg: Curupira e.V.

Naucke, Philipp; Maihold, Günther (2015). Kolumbiens Weg zum Frieden. Die Verhandlungen zwischen der Regierung und der FARC-Guerilla bedürfen internationaler Begleitung. SWP-Aktuell 2015/A 50. Berlin: Stiftung Wissenschaft und Politik - Deutsches Institut für Internationale Politik und Sicherheit.

Novkov, Julie; Barcklay, Scott (2010). "Lesbians, Gays, Bisexuals, and the Transgendered in Political Science: Report on a Discipline-Wide Survey." PS: Political Science and Politics, 43 (1): 95-106.

O’Brien, Kevin J. (1996). "Rightful Resistance.” World Politics, 49 (1): 31-55.

OECD (2015). OECD Economic Surveys. Colombia. Paris: Organization for Economic CoOperation and Development.

Ortiz Sarmiento, Carlos M. (1998) Urabá: tras las huellas de los inmigrantes 1955-1990. Bogotá: ICFES. 
Pizarro Leongómez, Eduardo (1996). Insurgencia sin revolución. La guerrilla en Colombia en una perspectiva comparada. Bogotá: tercer mundo editores.

PNUD (2011). Colombia rural. Razones para la esperanza. Informe Nacional de Desarrollo Humano 2011. Bogotá: INDH Programa de las Naciones Unidas para el Desarrollo.

- 2014. Informe sobre Desarrollo Humano 2014. Sostener el Progreso Humano: Reducir vulnerabilidades y construir resiliencia. Nueva York: Programa de las Naciones Unidas para el Desarrollo.

Ramírez Tobón, William (1997). Urabá: los inciertos confines de una crisis. Bogotá: Primera Plana.

Richards, Paul (Ed.) (2005). No Peace No War. An Anthropology of Contemporary Armed Conflicts. Athens: Ohio University Press.

Robben, Antonius (2004). "The Fear of Indifference: Combatants Anxities about the Political Identity of Civilians during Argentinas Dirty War." en N. Scheper-Hughes, P. Bourgois (Eds.), Violence in War and Peace. Malden, Oxford, Carlton: Blackwell Publishers, 200206.

Rojas, Catalina (2004). “The People's peace processes: Local resistance processes and the development of 'zone of peace' in Colombia.” Reflexión Politica, 6 (11): 70-87.

Roose, Jochen (2010). "Der endlose Streit um die Atomenergie. Konfliktsoziologische Untersuchung einer dauerhaften Auseinandersetzung." en P.H. Feindt, T. Saretzki (Eds.), Umwelt- und Technikkonflikte. Wiesbaden: VS Verlag für Sozialwissenschaften, 79-103.

Rowe, David (1998). "Play Up: Rethinking Power and Resistance in Sport." Journal of Sport \& Social Issues, 22 (3): 241-251.

Sahlins, Marshall (2002). Waiting for Foucault, Still. Chicago: Prickly Paradigm Press.

Sánchez, Fabian; Chacon, Mario (2006). “Conflicto, Estado y descentralización: del progreso social a la disputa armada por el control local, 1974-2002.” en F. Gutiérrez, M.E. Wills, G. Sánchez (Eds.), Nuestra guerra sin nombre: transformaciones del conflicto en Colombia. Bogotá: Editorial Norma, 347-403.

Sanford, Victoria D. L. (2004). "Contesting Displacement in Colombia, Citizenship and State Sovereignty at the Margins." en V. Das, D. Poole (Eds.), Anthropology in the Margins of the State. Santa Fe, Oxford: School of American Research Press, 253-78.

Schneckener, Ulrich (2006). Fragile Staatlichkeit: ,state at risk“ zwischen Stabilität und Scheitern. Baden-Baden: Nomos.

Scott, James C. (1985). Weapons of the Weak: Everyday Forms of Peasant Resistance. New Heaven, London: Yale University Press.

- 1990. Domination and the arts of resistance: hidden transcripts. New Heaven, London: Yale University Press.

Sharp, Gene (1973). The Politics of Nonviolent Action. Bosten: Porter Sargent.

Shaykhutdinov, Renat (2010). "Give peace a chance: Nonviolent protest and the creation of territorial autonomy arrangements.” Journal of Peace Research, 47 (2): 179-91.

Skocpol, Theda (2006). States and Social Revolutions: a comparative analysis of France, Russia and China. Cambridge: Cambridge University Press.

Stephan, Maria J., Chenoweth, Erica (2008). "Why Civil Resistance Works: The Strategic Logic of Nonviolent Conflict." International Security, 33 (1): 7-44.

Sudgen, John; Tomlinson, Alan (1998). "Power and Resistance in the Governance of World Football: Theorizing FIFA's Transnational Impact.” Journal of Sport \& Social Issues, 22 (3): 299-316.

Tomlinson, Alan (1998). "Power: Domination, Negotiation, and Resistance in Sport Cultures.” Journal of Sport \& Social Issues, 22 (3): 235-240. 
Tucker, James (1993). “Everyday Forms of Employee Resistance.” Sociological Forum, 8 (1): 25-45.

Uba, Katrin (2008). "Labor Union Resistance to Economic Liberalization in India: What Can National and State Level Patterns of Protests against Privatization Tell Us?" Asian Survey, 48 (5): 860-84.

Valenzuela, Pedro (2010). "La neutralidad como estrategia para la protección de la población civil en conflictos armados internos: un estudio de caso." en C. Churraca, D. Meertens (Eds.), Desplazamiento en Colombia: prevenir, asistir, transformar: cooperación internacional e iniciativas locales. Medellín: La Carreta Editores, 181-217.

Waldmann, Peter (1997). "Veralltäglichung von Gewalt: Das Beispiel Kolumbien.” en T. von Trotha (Ed.), Soziologie der Gewalt. Wiesbaden: VS Verlag für Sozialwissenschaften, 141-59.

Weitz, Rose (2001). "Woman and Their Hair: Seeking Power through Resistance and Accomodation." Gender and Society, 15 (5): 667-686.

Wickham-Crowley, Timothy P. (1993). Guerrillas and Revolution in Latin America: a comparative study of insurgent and regimes since 1956. Princeton: Princeton University Press.

Zelik, Raul(1999). Kolumbien: große Geschäfte, staatlicher Terrorund Aufstandsbewegungen. Köln: Neuer ISP-Verlag.

— 2009. Die kolumbianischen Paramilitärs. >Regieren ohne Staat?< oder terroristische Formen der inneren Sicherheit. Münster: Westfälisches Dampfboot. 